Jurnal Kesehatan Hesti Wira Sakti Vol 8 No 12020

ISSN 2302-4283 (print)

ISSN 2580-9571 (online)

Online di https://jurnal.poltekkes-soepraoen.ac.idDOI: 10.47794/jkhws

\title{
MENGATASI NYERI TRIGEMINAL NEURALGIA DENGAN AKUPUNKTUR DI KLINIK AKUPUNKTUR MANDIRI “E” MALANG
}

\author{
Astiana Hadiah Ningsih ${ }^{1)}$ Puspo Wardoyo ${ }^{2)}$ \\ ${ }^{1)}$ Akupunktur Terapis di Poli Akupunktur RS Islam Aisyah Malang \\ Email : astihadiah7@gmail.com \\ ${ }^{2)}$ Prodi Akupunktur ITSK RS dr. Soepraoen Kesdam V Malang \\ Email : puspowardoyo45@gmail.com
}

\begin{abstract}
ABSTRAK
Pendahuluan. Nyeri trigeminal neuralgia dirasakan sebagai sensasi sakit di wajah yang datang secara tibatiba dan menyebar ke area rahang, pipi dan dahi. Trigeminal neuralgia merupakan kondisi yang sangat menyakitkan dan sulit untuk diobati. Trigeminal neuralgia jarang terjadi, tetapi dapat mempengaruhi 4 hingga 13 orang per 100.000 di seluruh dunia. Prevalensi kasus nyeri neuropatik, termasuk nyeri trigeminal di RSHS Bandung sebanyak 31,6\% dari 736 subyek. Hampir 75\% kasus mengalami nyeri kronis. Terapi farmakologi dan bedah tetap digunakan sesuai kebutuhan. Terapi akupunktur yang bereputasi membantu meredakan nyeri menjadi alternatif terpilih dalam kasus trigeminal neuralgia. Metode. Kasus trigeminal neuralgia tidak banyak sehingga sampel diambil menggunakan teknik total sampling. Lima titik akupunktur klasik Yifeng (TE 17), Fengchi (GB 20), Fengmen (BL 12), Lieque (LU 07), dan Hegu (LI 04) dipilih berdasarkan pada jenis sindrom terbanyak, yaitu serangan angina dingin luar. Pengukuran nyeri penggunakan skala nyeri Bourbanis. Teknik analisis data menggunakan uji wilcoxon signed rank test interpretation. Hasil. Terbukti ada perbedaan nyeri sebelum dan sesudah terapi akupunktur. Rata-rata tingkat nyeri sebelum terapi adalah $47 \%$ dan sesudah terapi $14 \%$. Kesimpulan. Terapi akupunktur dapat mengatasi nyeri trigeminal neuralgia. Dengan demikian terapi akupunktur yang tanpa obat dan tanpa bedah direkomendasikan untuk diterapkan di fasilitas pelayanan kesehatan lain.
\end{abstract}

Kata Kunci : Akupunktur, Intensitas Nyeri, Trigeminal Neuralgia

\begin{abstract}
Preliminary. Trigeminal neuralgia pain is felt as a painful sensation in the face that comes on suddenly and radiates to the jaw, cheek and forehead area. Trigeminal neuralgia is a very painful condition and is difficult to treat. Trigeminal neuralgia is rare, but can affect 4 to 13 people per 100,000 worldwide. The prevalence of neuropathic pain cases, including trigeminal pain in RSHS Bandung was $31.6 \%$ of 736 subjects. Nearly $75 \%$ of cases have chronic pain. Pharmacological and surgical therapy is still used as needed. Acupuncture therapy with a reputation for helping to relieve pain is the alternative of choice in cases of trigeminal neuralgia. Method. There are not many cases of trigeminal neuralgia, so the sample was taken using a total sampling technique. Five classic acupuncture points Yifeng (TE 17), Fengchi (GB 20), Fengmen (BL 12), Lieque (LU 07), and Hegu (Fact Sheet 04) were selected based on the most common type of syndrome, namely attacks of external cold angina. Pain measurement using the Bourbanis pain scale. The data analysis technique used the Wilcoxon signed rank test interpretation. Results. It was proven that there was a difference in pain before and after acupuncture therapy. The mean level of pain before therapy was $47 \%$ and after therapy was $14 \%$. Conclusion. Acupuncture therapy can treat trigeminal neuralgia pain. Thus, acupuncture therapy without drugs and without surgery is recommended to be applied in other health care facilities.
\end{abstract}


Jurnal Kesehatan Hesti Wira Sakti Vol 8 No 12020

ISSN 2302-4283 (print)

ISSN 2580-9571 (online)

Online di https://jurnal.poltekkes-soepraoen.ac.idDOI: 10.47794/jkhws

Keywords: Acupuncture, Pain Intensity, Trigeminal Neuralgia

\section{PENDAHULUAN}

Trigeminal neuralgia adalah nyeri yang tiba-tiba, biasanya satu sisi, nyeri sangat seperti tertusuk dan berulang didistribusi oleh satu atau lebih cabang saraf kranialis ke-5. Menurut IHS (International Headache Society), trigeminal neuralgia adalah nyeri satu sisi wajah yang menyakitkan, ditandai dengan nyeri terbatas seperti kejutan listrik singkat untuk mendistribusi bagian satu atau yang lain dari saraf trigeminal (Srivastava, R., et al. 2015).

Nyeri biasanya ditimbulkan oleh rangsangan sepele termasuk mencuci, mencukur, merokok, berbicara dan menyikat gigi, tapi mungkin juga terjadi secara spontan. Nyeri mendadak saat terjadi serangan dan terminasi yang beralih dalam periode yang bervariasi. Sehingga trigeminal neuralgia menimbulkan efek yang dapat mengganggu kegiatan seseorang dalam menjalankan kehidupan sehari-hari, misalnya seperti kesulitan berbicara, berdandan, bercukur, mencuci wajah, menyikat gigi, menggigit dan mengunyah makanan (Julie, G., \& Olga, K., 2019).

Patofisiologi Trigeminal Neuralgia sampai sekarang ini masih ada dua pendapat, yang pertama mengatakan gangguan mekanisme saraf perifer sebagai penyebab terjadinya trigeminal neuralgia, dan yang kedua mengatakan gangguan mekanisme sentral sebagai penyebab trigeminal neuralgia. Aktivasi dari reseptor, transmisi dan proyeksi dari informasi nosiseptif, konvergensi dari serabut afferen nosiseptif menuju sistem saraf pusat, dan interaksi antara neurotransmiter dan neuromodulator merupakan beberapa mekanisme neurofisiologik yang terlibat dalam trigeminal neuralgia (Costa dan Leite, 2015).

Nilotpol, K., et al. (2019) Angka kejadian TN adalah sekitar 3 sampai 5 kasus/tahun/100.000 orang. Prevalensi diperkirakan 107,5 laki-laki dan 200,2 perempuan/1 juta penduduk. Penyakit ini lebih sering terjadi pada sisi kanan wajah dibandingkan dengan sisi kiri, dan merupakan penyakit pada kelompok usia dewasa (dekade enam sampai tujuh). Mark, et al. (2019) menyebutkan bahwa trigeminal neuralgia ditandai dengan serangan berulang dari nyeri wajah yang menusuk pada distribusi dermatomal saraf trigeminal. Trigeminal neuralgia memang jarang terjadi, namun demikian nyeri ini bias mempengaruhi 4 hingga 13 orang per 100.000 pada populasi dunia.

Terapi pada trigeminal neuralgia ada 2 macam yaitu terapi medikamentosa dan terapi pembedahan. Telah disepakati bahwa penanganan lini pertama untuk trigeminal neuralgia adalah terapi medikamentosa. Meskipun efektif, ada keterbatasan dan kekurangan dalam terapi farmakologis dan bedah pada pengobatan trigeminal neuralgia (Liu, 2019). Saat ini obatobatan yang digunakan untuk terapi Trigeminal Neuralgia adalah obat- obatan anti konvulsi 
Jurnal Kesehatan Hesti Wira Sakti Vol 8 No 12020

ISSN 2302-4283 (print)

ISSN 2580-9571 (online)

Online di https://jurnal.poltekkes-soepraoen.ac.idDOI: 10.47794/jkhws

seperti karbamazepine (tegretol), phenitoin

(dilandin), oxykarbazepine (trileptal) dan

gabapentin (neurontin). Tidak seperti sakit

neuropatik lainnya, trigeminal neuralgia hanya

merespon anti konvulsan dan tidak merespon anti depresan atau opioid. Obat anti konvulsan dapat mengurangi serangan trigeminal neuralgia dengan menurunkan hiperaktifitas nukleus nervus trigeminus di dalam brain stem (Julie, G., \& Olga, K., 2019).

Ada pula terapi nonfarmakologis untuk mengatasi nyeri pada trigeminal neuralgia yaitu dengan terapi akupunktur. Akupunktur merupakan suatu teknik terapi kesehatan dengan cara memasukkan dan memanipulasi jarum ke dalam titik akupunktur tubuh. Cara ini dapat memulihkan kesehatan dan kebugaran khususnya sangat baik untuk mengobati rasa sakit yang diderita pasien. Definisi serta karakterisasi titiktitik akupunktur ini distandarisasikan oleh World Health Organization (WHO).

Menurut Goldman, et al. (2010) akupunktur dapat mengurangi rasa nyeri karena jarum akupunktur memicu dilepaskannya adenosin yang merupakan salah satu zat penghilang rasa sakit alami. Selain dapat mengurangi rasa nyeri, peningkatan tingkat adenosin juga dapat menimbulkan efek menenangkan.

Pada tahun 2018 terdapat 25 pasien trigeminal neuralgia, yang termasuk urutan ketiga terbanyak dari kasus nyeri dan stroke. Awalnya pasien-pasien tersebut adalah rujukan dari Poli
Gigi di rumah sakit tersebut, sehingga setiap ada pasien yang didiagnosa sebagai trigeminal neuralgia akan dirujuk ke Klinik Akupunktur Mandiri "E" Malang ini.

\section{METODE PENELITIAN}

Penelitian ini dilakukan di Klinik Akupunktur Mandiri "E" Malang. Klinik ini berada dalam satu lingkup Rumah Sakit Islam Aisyah Malang. Akupunkturis di klinik tersebut telah banyak menangani berbagai penyakit, salah satunya penyakit yang menarik untuk dijadikan sebagai penelitian yaitu penyakit trigeminal neuralgia.

Desain penelitian ini menggunakan pendekatan Pre-Experimental Design dengan Pre-Test and Post-Test Design (Sugiyono, 2014). Penelitian ini bertujuan untuk mengetahui gejala atau pengaruh yang timbul sebagai akibat dari adanya perlakuan akupunktur terhadap intensitas nyeri pasien trigeminal neuralgia. Jumlah responden dalam penelitian ini hanya 10 subyek sehingga sampel yang dipilih menggunakan teknik total sampling. Awalnya pasien-pasien tersebut adalah rujukan dari Poli Gigi di rumah sakit tersebut, sehingga setiap ada pasien yang didiagnosa sebagai trigeminal neuralgia akan dirujuk ke Klinik Akupunktur Mandiri "E" Malang ini.

Pengumpulan data dilakukan dengan cara mengukur intensitas nyeri responden sebelum mendapat tindakan terapi akupunktur dengan menggunakan lembar kuesioner Skala Nyeri Borbanis. Setiap pasien yang akan diterapi 
Jurnal Kesehatan Hesti Wira Sakti Vol 8 No 12020

ISSN 2302-4283 (print)

ISSN 2580-9571 (online)

Online di https://jurnal.poltekkes-soepraoen.ac.idDOI: 10.47794/jkhws

diminta mengisi lembar kuesioner lebih dulu.

Dalam pengisian kuesioner dapat dibantu oleh petugas pengumpul data sesuai pengakuan pasien yang merasakan sensasi nyeri setelah menandatangani informed consent. Data awal ini sebagai data pre-test. Sedangkan data post-test diambil setelah pasien menjalani terapi akupunktur sebanyak 10 kali terapi (3 kali terapi per minggu). Analisis data dalam penelitian ini menggunakan Uji Tanda Wilcoxon, yaitu uji statistik sederhana yang efektif untuk menghitung data kecil, kurang dari 30 subyek (Sunyoto, 2013).

\section{HASIL PENELITIAN}

Penelitian ini mendapatkan data umum dan data khusus responden. Data umum responden ditunjukkan dengan persentase meliputi : sebagian besar responden berumur di atas 60 tahun (50\%), jenis kelamin responden sebagian besar perempuan (70\%), pekerjaan responden sebagian besar ibu rumah tangga (50\%), sindroma Penyebab Penyakit Luar Angin Dingin sebagai sindroma terbanyak (50\%), intensitas nyeri yang dirasakan responden sebelum mendapat layanan terapi terbanyak pada skala nyeri Sedang (50\%), sedangkan setelah sesi akhir terapi intensitas nyeri responden terbanyak berada pada skala nyeri Ringan (70\%).

Tabel 1 : Klasifikasi Nyeri

\begin{tabular}{ccc}
\hline \multirow{2}{*}{ Klasifikasi } & \multicolumn{2}{c}{ Jumlah } \\
\cline { 2 - 3 } & Sebelum & Sesudah \\
\hline Tidak Nyeri & 0 & $3(30 \%)$ \\
\hline Nyeri Ringan & $3(30 \%)$ & $7(70 \%)$ \\
\hline
\end{tabular}

\section{Sumber : Data Primer}

Berikut ini bentuk lain tampilan data khusus.

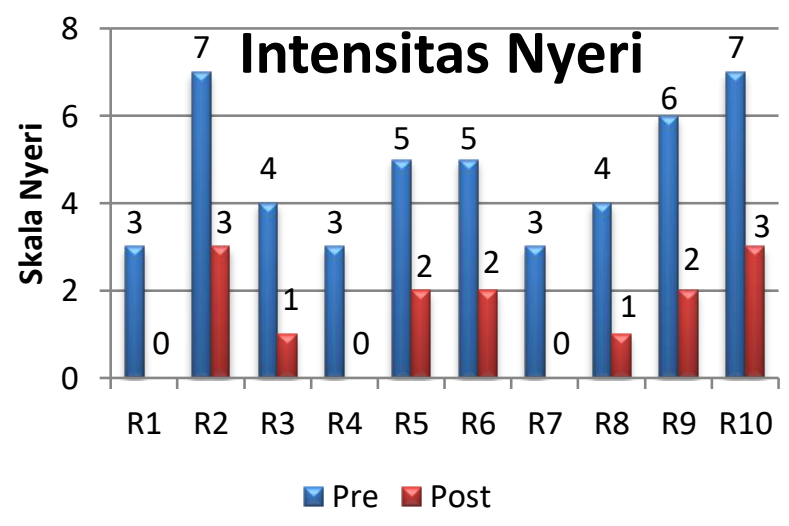

Gambar 1 : Intensitas Nyeri Responden

Dari tabel 1 maupun gambar 1 dapat diketahui bahwa semua responden yang menderita 
Jurnal Kesehatan Hesti Wira Sakti Vol 8 No 12020

ISSN 2302-4283 (print)

ISSN 2580-9571 (online)

Online di https://jurnal.poltekkes-soepraoen.ac.idDOI: 10.47794/jkhws

nyeri trigeminal neuralgia mengalami penurunan.

Tingkat perunuran antar responden berbeda-beda.

Ada tujuh responden mengalami penurunan intensitas nyeri tiga tingkat. Sedangkan tiga responden mengalami penurunan tingkat nyeri empat tingkat. Sebanyak tiga responden mengaku tidak merasakan adanya nyeri atau sembuh (skala 0) dan responden lainnya masih merasakan nyeri ringan (skala $1-3$ ).

Dari tabel tersebut diketahui juga bahwa jumlah "selisih" = 33, sedangkan jumlah "sebelum" = 47. Jika dibandingkan maka hasilnya $=70$. Jadi besarnya pengaruh terapi akupunktur terhadap intensitas nyeri trigeminal neuralgia sebesar $70 \%$.

Analisis data menggunakan uji peringkat bertanda Wilcoxon, yaitu membandingkan hasil $\mathrm{t}$ hitung dengan hasil $\mathrm{t}$ tabel. Hasil $\mathrm{t}$ hitung $=0$, sedangkan t tabel (pada 10 resonden dengan $\alpha$ $0,05)=8$. Dengan demikian nilai $t$ hitung $(0)<t$ tabel (8). Karena t hitung lebih kecil dari t tabel, maka $\mathrm{H}_{0}$ ditolak, berarti ada pengaruh terapi akupunktur terhadap intensitas nyeri trigeminal neuralgia.

\section{PEMBAHASAN}

Penelitian ini menghasilkan data bahwa kelompok jenis kelamin penderita trigeminal neuralgia yang terbanyak perempuan $(70 \%)$ dan sisanya laki-laki (30\%). Kelompok usia penderita trigeminal neuralgia terbanyak pada usia 60 tahun ke atas. Dari sisi pekerjaan didapatkan data bahwa dibandingkan dengan jenis pekerjaan lain maka ibu rumah tangga paling banyak mengalami nyeri trigeminal neuralgia sebanyak (50\%).

Selaras dengan ini, (Cohen, J., 2014), menyebutkan bahwa neuralgia trigeminal diderita wanita sedikit lebih sering daripada pria. Meskipun kejadian pastinya tidak diketahui, sekitar 10.000-15.000 kasus baru terjadi setiap tahun di Amerika Serikat. Gangguan ini paling sering menyerang individu yang berusia lebih dari 50 tahun. Namun, kasus dapat terjadi pada orang dewasa yang lebih muda juga. Pada individu yang lebih muda, penyebabnya sering idiopatik, tetapi jika dibandingkan dengan kasus dewasa yang lebih tua lebih mungkin disebabkan oleh kerusakan sistem saraf pusat seperti pada individu dengan multiple sclerosis. Meskipun sangat jarang, trigeminal neuralgia dapat terjadi pada anak-anak.

Dalam perspektif kedokteran timur penggolongan sindrom penderita trigeminal neuralgia yang terbanyak adalah kelompok Serangan Penyebab Penyakit Luar Angin Dingin (50\%). Faktor penyebabnya adalah karena banyak penderita yang sering terpapar angin dingin luar atau akibat terlalu sering mengkonsumsi makanan dan minuman yang dingin dan mentah. You (2008), menyebutkan bahwa Serangan Penyebab Penyakit Luar Angin Dingin yang paling sering terjadi yaitu bila patogen angin dingin menyerang meridian Yangming sehingga membekukan darah, menyumbat meridian, Qi Xue (bio-energi, drah) tersumbat, tidak lancar maka terjadi nyeri wajah atau trigeminal neuralgia. Hal senada 
Jurnal Kesehatan Hesti Wira Sakti Vol 8 No 12020

ISSN 2302-4283 (print)

ISSN 2580-9571 (online)

Online di https://jurnal.poltekkes-soepraoen.ac.idDOI: 10.47794/jkhws

disampaikan Jihe, Z., et al. (2017), saraf trigeminal memiliki 3 cabang, satu ke mata, yang kedua ke mulut, dan yang ketiga ke rahang. Menurut pengobatan tradisional China, mereka keluar di sekitar area taiyang wajah dan dari perspektif pengobatan tradisional China, neuralgia trigeminal memiliki etiologi multifaktorial:

1. Eksterior - Invasi Angin Dingin

2. Interior - Api Hati / Lambung

3. Interior - Defisiensi Yin dengan kosong api naik.

Intensitas nyeri yang dirasakan responden sebelum pemberian terapi akupunktur terbanyak adalah mengalami nyeri sedang (50\%). Sedangkan setelah pemberian terapi akupunktur semua responden dengan berbagai karakteristiknya mengalami penurunan nilai intensitas nyeri.

Kim, Jong-In. et al. (2018) menulis bahwa trigeminal neuralgia adalah jenis nyeri kronis yang parah yang ditandai dengan nyeri seperti sengatan listrik singkat di satu atau lebih divisi saraf trigeminal. Frekuensi, durasi, dan keparahan serangan yang menyakitkan ini secara bertahap meningkat. Dengan demikian mereka sering menjadi kebal terhadap obat. Oleh karena itu neuralgia menjadi kronis dan dapat sangat mempengaruhi kualitas hidup dan menyebabkan gangguan kognitif seperti kecemasan dan depresi pada sebagian besar pasien dengan trigeminal neuralgia.

Mekanisme aksi mendasari efek akupunktur pada pengendalian nyeri yang disebut analgesia akupunktur. Mekanisme ini telah dieksplorasi sehubungan dengan mekanisme perifer dan sentral. Dengan memasukkan jarum akupunktur ke titik akupunktur akan menghasilkan sensasi de-qi. Sensasi ini berindikasi menggairahkan semua serat aferen dari jaringan otot.

Sert, H. (2009) dalam penelitiannya menyebutkan bahwa banyak pasien dengan trigeminal neuralgia akhirnya menjadi refrakter terhadap terapi obat dan beberapa kasus mengembangkan resistensi terhadap modalitas perawatan bedah. Selain itu, efek samping yang serius dapat terjadi, terutama dengan penggunaan metode bedah. Dengan demikian, pasien-pasien ini ditempatkan da-lam situasi yang sulit. Mereka mengunjungi beberapa dokter karena rasa sakit yang tak tertahankan. Pendekatan alternatif diperlukan untuk menyembuhkan pasien ini.

Mervyn, T. (2019) menyebutkan bahwa Obat berupa analgesik (parasetamol dan aspirin) dan tablet anti inflamasi (ibuprofen) tidak efektif untuk nyeri trigeminal neuralgia. Antikonvulsan yang biasa digunakan untuk trigeminal neuralgia adalah: carbamazepine (Tegretol, Carbatrol, Epitol), oxycarbazepine (Trileptal), baclofen (Lioresal), gabapentin (Neurontin), asam valproat (Depakene, Depakote), fenitoin (Dilantin), topiramate (Topamax) dan lamotrigin (Lamictal) yang telah ditemukan efektif sebagai berbagai pengobatan kombinasi atau pengobatan yang berdiri sendiri untuk trigeminal neuralgia. Efek samping umum dari antikonvulsan meliputi: mual, 
Jurnal Kesehatan Hesti Wira Sakti Vol 8 No 12020

ISSN 2302-4283 (print)

ISSN 2580-9571 (online)

Online di https://jurnal.poltekkes-soepraoen.ac.idDOI: 10.47794/jkhws

pusing, kebingungan, kantuk, masalah penglihatan, pikiran untuk bunuh diri dan alergi.

Obat anti-epilepsi, termasuk carbamazepine, adalah pilihan pengobatan lini pertama untuk trigeminal neuralgia, tetapi mereka sering gagal untuk menghilangkan rasa sakit dan/atau menghasilkan efek samping yang signifikan seperti gangguan kognitif, kehilangan memori, dan penekanan sumsum tulang. Di antara intervensi bedah, operasi dekompresi mikrovaskular mungkin merupakan metode yang efektif untuk menyembuhkan trigeminal neuralgia. Namun, ini terbatas pada konflik neurovaskular dalam kompresi vaskular dari akar saraf trigeminal pada dewasa muda atau orang tua yang sehat dan sekitar setengah dari kasus mengalami nyeri berulang. Oleh karena itu, akupunktur dapat menjadi pilihan untuk mengendalikan nyeri pada trigeminal neuralgia (Kim, Jong-In. et al. 2018).

Akupunktur klasik dipilih sebagai teknik terapi komplementer atau alternatif untuk pengobatan beberapa penyakit kronis dan pengendalian nyeri. Efek analgesik akupunktur terjadi karena meningkatnya kadar mediator, termasuk endorphin, encephalin dan serotonin dalam plasma dan jaringan otak.

Akupunktur merupakan prosedur yang sangat aman dengan beberapa komplikasi dan efek samping ringan, di antaranya adalah memar atau hematoma di tempat jarum, alergi logam dan infeksi lokal. Dengan demikian akupunktur yang hampir tidak memiliki efek samping dapat

menjadi metode pengobatan alternatif untuk pasien yang resistan terhadap carbamazepine dan oxcarbazepine .

\section{KESIMPULAN}

Akupunktur menghasilkan efek menguntungkan pada sebagian besar pasien dalam penelitian ini. Akupunktur terbukti aman dan efektif untuk mengobati nyeri trigeminal neuralgia sehingga dapat menjadi inspirasi topik untuk peneliti selanjutnya. Selain itu, akupunktur harus dipertimbangkan oleh dokter untuk mengelola nyeri trigeminal neuralgia sebagai pilihan terapi yang aman pada pasien terutama sebelum intervensi invasif dilakukan.

\section{DAFTAR PUSTAKA}

Agfiandi, DB., Sadeli, HA., Dikot, Yustiani. (2015). Prevalensi dan karakteristik nyeri neuropatik di instalasi rawat jalan neurologi Rs dr. Hasan sadikin bandung. http://www.neurona.web.id/paper.do

Diakses tanggal 2 Februari 2019

Cohen, Jeffrey. (2014). Trigeminal neuralgia. ational Organization for Rare Disorders (NORD). National Organization for Rare Disorders (NORD) 55 Kenosia Ave., Danbury CT.

Costa, G.M.F., and Leite, C.M.A. (2015). Trigeminal neuralgia: peripheral and central mechanism. Rev Dor. São Paulo

Di Stefano G, Maarbjerg S, Truini A. (2019). Trigeminal neuralgia secondary to multiple sclerosis: from the clinical picture to the treatment

options. 
Jurnal Kesehatan Hesti Wira Sakti Vol 8 No 12020

ISSN 2302-4283 (print)

ISSN 2580-9571 (online)

Online di https://jurnal.poltekkes-soepraoen.ac.idDOI: 10.47794/jkhws

https://pubmed.ncbi.nlm.nih.gov/2730663/

Diakses tanggal 2 Februari 2019.

Goldman, N. et.al. (2010). Adenosin Al receptors mediate local anti-nociceptive effects of acupuncture. Nature Neuroscience.

Jihe, Z., Blagica Arsovska, Kristina Kozovska, Karolina Nikolovska. Two Case Reports: Acupuncture Treatment for Trigeminal Neuralgia. American Journal of Health Research. Vol. 5, No. 3, 2017, pp. 54-56. doi: 10.11648/j.ajhr.20170503.11

Julie G. Pilitsis \& Olga Khazen. (2019). trigeminal neuralgia.

https://www.aans.org/Patients/Neurosurgic al-Conditions-and-Treatments/TrigeminalNeuralgia Diakses tanggal 2 Februari 2019.

Kim, J.I., et al. (2018). Acupuncture for the treatment of trigeminal neuralgia : A protocol for the systematic review of randomized controlled trials. https://www.ncbi.nlm.nih.gov/pmc/articles /PMC5882395/ Diakses tanggal 2 Februari 2019.

Liu, Hao; Li, Xin-Wei; Du, Jia. (2019) Acupuncture treatment on idiopathic trigeminal neuralgia: A systematic review protocol. Medicine. 98(4): e14239, January 2019.

Loeser JD. (2001). Cranial Neuralgia, In : Banica's Management of Pain, u i Philadelphia, Lipincott William \& Wilkins

Mark R Jones, et al. (2019). A Comprehensive Review of trigeminal Neuralgia. https://pubmed.ncbi.nlm.nih.gov/31388843

I Diakses tanggal 12 Agustus 2019

Mervyn, Turton. (2019). Trigeminal neuralgia: case report and literature review. https://sdsjournal.com/article/view/3174

Diakses pada tanggal 2 Agustus 2019.

Nilotpol Kashyap., et al. Trigeminal Neuralgia: Case Report and Treatment Modalities. Acta Scientific Dental Sciences 3.10 (2019): 64-66 Diakses 2 Februari 2019

Nurmikko T J, Eldridge P R., 2001, Trigeminal Neuralgia- Patho-physiology, Diagnosis and Current Treatment. British Journal of Anaesthesia, 87, 32-117.

Riawan, Lucky. (2007). Terapi Medikamentosa pada Trigeminal Neuralgia. Bandung : Universitas Padjajaran.

Sert, H,. (2009). Successful Treatment of a Resistance Trigeminal Neuralgia Patient By Acupuncture. https://www.ncbi.nlm.nih.gov/pmc/articles /PMC2797593/ Diakses pada tanggal 2 Februari 2019.

Srivastava, R., Jyoti, B., Shukla, Rahul., Priyadarshi, P. (2015). Diagnostic criteria and management of trigeminal neuralgia: $\mathrm{A}$ review. Asian Pac. J. Health Sci.; 2(1): 108118.

https://core.ac.uk/download/pdf/326494108 .pdf Diakses tanggal 2 Februari 2019.

Sugiyono. (2014). Metode Penelitiaan Kuantitatif Kualitatif \& RND. Bandung : Alfabeta 
Jurnal Kesehatan Hesti Wira Sakti Vol 8 No 12020

ISSN 2302-4283 (print)

ISSN 2580-9571 (online)

Online di https://jurnal.poltekkes-soepraoen.ac.idDOI: 10.47794/jkhws

Sunyoto, D. dan Ari, S. (2013). Statistik Kesehatan

Paramatrik, Non Paramatrik, Validitas, dan

Reliabilitas. Yogyakarta : Nuha Medika

You, Pu Lian. Zhang Xue Li. (2008). Zhenjiu

Linchuang Shouce. Beijing : Renmin

Weisheng Chubanshe. 